\title{
Hedge Funds and the Technology Bubble
}

\author{
MARKUS K. BRUNNERMEIER and STEFAN NAGEL*
}

\begin{abstract}
This paper documents that hedge funds did not exert a correcting force on stock prices during the technology bubble. Instead, they were heavily invested in technology stocks. This does not seem to be the result of unawareness of the bubble: Hedge funds captured the upturn, but, by reducing their positions in stocks that were about to decline, avoided much of the downturn. Our findings question the efficient markets notion that rational speculators always stabilize prices. They are consistent with models in which rational investors may prefer to ride bubbles because of predictable investor sentiment and limits to arbitrage.
\end{abstract}

Technology stocks on NASDAq Rose to unprecedented levels during the 2 years leading up to March 2000. Ofek and Richardson (2002) estimate that at the peak, the entire internet sector, comprising several hundred stocks, was priced as if the average future earnings growth rate across all these firms would exceed the growth rates experienced by some of the fastest growing individual firms in the past, and, at the same time, the required rate of return would be $0 \%$ for the next few decades. By almost any standard, these valuation levels are so extreme that this period appears to be another episode in the history of asset price bubbles.

Shiller (2000) argues that the stock price increase was driven by irrational euphoria among individual investors, fed by an emphatic media, which maximized TV ratings and catered to investor demand for pseudonews. Of course, only few economists doubt that there are both rational and irrational market participants. However, there are two opposing views about whether rational traders correct the price impact of behavioral traders. Proponents of the

\footnotetext{
*Markus K. Brunnermeier is affiliated with Princeton University and CEPR and Stefan Nagel with Stanford University. We would like to thank Cliff Asness, Richard Brealey, Smita Brunnermeier, Elroy Dimson, Gene Fama, Bill Fung, Rick Green (the editor), Martin Gruber, Tim Johnson, Jon Lewellen, Andrew Lo, Burt Malkiel, Narayan Naik, Aureo de Paula, Lukasz Pomorski, Jeff Wurgler, and two anonymous referees as well as participants at the European Finance Association Meetings, the Fall 2002 NBER Behavioral Finance Meetings, and in seminars at the Board of Governors of the Federal Reserve System, Federal Reserve Bank of New York, University of Chicago, London Business School, MIT, Northwestern University and Princeton University for useful comments. Part of this research was undertaken while both authors were visiting the Sloan School of Management at MIT and while Nagel was a doctoral student at London Business School. Brunnermeier acknowledges research support from the National Science Foundation (NSF-Grant no. 021-4445). Nagel is grateful for financial support from the ESRC, the Lloyd's Tercentenary Foundation, the Kaplanis Fellowship, and the Centre for Hedge Fund Research and Education at London Business School.
} 
efficient markets hypothesis (Friedman (1953), Fama (1965)) argue that rational speculative activity would eliminate not only riskless arbitrage opportunities, but also other forms of mispricing whose exploitation may require imperfectly hedged and therefore risky trades. The latter case clearly applies to the technology bubble, as there does not exist a close substitute that could be used to hedge a short position in the technology sector. In contrast, the literature on limits to arbitrage points out that various factors such as noise trader risk, agency problems, and synchronization risk may constrain arbitrageurs and allow mispricing to persist. Moreover, some models indicate that rational investors might find it optimal to ride bubbles for a while before attacking them, making the actions of rational investors destabilizing rather than stabilizing.

To shed some light on these issues, we examine empirically the response of hedge funds to the growth of the technology bubble. Hedge funds are among the most sophisticated investors-probably closer to the ideal of "rational arbitrageurs" than any other class of investors. Our aim is to find out whether sophisticated speculators were indeed a correcting force during the bubble period. Our study is unusual in that we look directly at hedge fund holdings. In general, data on hedge funds are difficult to obtain because hedge funds are not regulated by the SEC. However, like other institutional investors, hedge funds with large holdings in U.S. equities do have to report their quarterly equity long positions to the SEC on Form 13F. We extract hedge fund holdings from these data, including those of well-known managers such as Soros, Tiger, Tudor, and others. To the best of our knowledge, our paper is the first to use holdings data to analyze the trading activities of hedge funds. To assess the effect of short positions and derivatives, we also look at the returns of hedge funds.

This empirical investigation yields several interesting results. First, our analysis indicates that hedge funds were riding the technology bubble. Over our sample period 1998 to 2000, hedge fund portfolios were heavily tilted toward highly priced technology stocks. The proportion of their overall stock holdings devoted to this segment was higher than the corresponding weight of technology stocks in the market portfolio. Relative to market portfolio weights, the technology exposure of hedge funds peaked in September 1999, about 6 months before the peak of the bubble. Hedge fund returns data reveal that this exposure on the long side was not offset by short positions or derivatives.

Second, we find that that the hedge funds in our sample skillfully anticipated price peaks of individual technology stocks. On a stock-by-stock basis, they started to cut back their holdings before prices collapsed, switching to technology stocks that still experienced rising prices. As a result, hedge fund managers captured the upturn, but avoided much of the downturn. This is reflected in the fact that hedge funds earned substantial excess returns in the technology segment of the Nasdaq. A portfolio that mimics their holdings exhibits abnormal returns of around $4.5 \%$ per quarter relative to a characteristics-matched benchmark, which controls for size, value, and momentum effects. Interestingly, this outperformance is confined to the technology sector; it does not show up in other market segments. This is consistent with the view that hedge fund managers 
were able to predict some of the investor sentiment that was arguably behind the wild fluctuations in valuations of technology stocks at the time. It also suggests that the technology exposure of hedge funds cannot simply be explained by unawareness of the bubble.

The fact that highly sophisticated investors were riding the bubble and profited from doing so is consistent with some recent theoretical results on limits of arbitrage. Our findings relate to two main insights in this literature. First, rational investors may be reluctant to trade against mispricing. Risk aversion limits their aggressiveness if close substitutes are unavailable and arbitrageurs therefore have to bear fundamental risk, as is the case, for example, in Wurgler and Zhuravskaya (2002). Abreu and Brunnermeier (AB) (2002, 2003) argue that synchronization risk can prevent arbitrageurs from attacking mispricing because each trader is uncertain about when other traders will sell out. Since a single investor cannot bring the market down by himself, coordination among rational traders is required and a synchronization problem arises. ${ }^{1}$ This allows the mispricing to persist for some time. In DeLong et al. (DSSW) (1990a), short horizons make arbitrageurs averse to noise trader risk caused by the possibility of temporary deepening of mispricing; in Dow and Gorton (1994), myopia leads them to trade only on information they expect to influence prices in the short run. Shleifer and Vishny (1997) argue that the short-horizon assumption is realistic in delegated portfolio management because temporary losses would lead to fund outflows. Consistent with this view, Chevalier and Ellison (1997) document that badly performing mutual funds experience fund outflows. Agarwal, Daniel, and Naik (2002) find similar flow-performance sensitivity for hedge funds, despite contractual arrangements designed to prevent outflows (e.g., lock-up provisions). As a related point, we show that different exposure to the technology segment during the bubble period coincided with very different flow patterns for two prominent hedge funds managers (Tiger and Soros).

Reasoning along these lines can explain why rational investors would not trade aggressive enough to completely eradicate mispricing. Nevertheless, their trades would still be stabilizing, in the sense that they would still want to short assets they know to be overpriced. Under certain circumstances, however, it can even be optimal for rational investors to invest in overpriced assets. In the coordination-failure model of $\mathrm{AB}$ (2003), a price bubble is growing unless a sufficient number of arbitrageurs decide to attack. As a result, arbitrageurs who conclude that other arbitrageurs are yet unlikely to trade against the bubble find it optimal to ride the still-growing bubble for a while. In DSSW (1990b), rational investors anticipate demand from positive feedback traders. If there is good news today, rational traders buy and push the price beyond its fundamental value because feedback traders are willing to take up the position at

\footnotetext{
${ }^{1}$ With respect to hedge funds, the assumption that some coordination would be required to burst a bubble seems reasonable, as the capital of the largest hedge funds rarely exceeds $\$ 20$ billion. Even taking into account their ability to use leverage, this is rather small compared with a combined market capitalization of all Nasdaq stocks in excess of \$5 trillion in 1999.
} 
a higher price in the next period. ${ }^{2}$ In both models, the incentive to ride the bubble stems from predictable "sentiment": anticipation of continuing bubble growth in AB (2003) and predictable feedback trader demand in DSSW (1990b). An important implication of these theories is that rational investors should be able to reap gains from riding a bubble at the expense of less sophisticated investors. Both predictions-sophisticated investors riding the bubble and gains from doing so-are consistent with our findings.

Overall, our evidence casts doubt on the presumption underlying the efficient markets hypothesis that it is always optimal for rational speculators to attack a bubble. While the exact implications of our results for the mechanism limiting the forces of arbitrage may be open to different interpretations, two points seem clear: First, there is no evidence that hedge funds as a whole exerted a correcting force on prices during the technology bubble. Among the few large hedge funds that did, the manager with the least exposure to technology stocks-Tiger Management-did not survive until the bubble burst. Second, it appears that aversion to arbitrage risk and frictions such as short-sales constraints alone are not sufficient to understand the failure of rational speculative activity to contain the bubble. While they may explain the unwillingness of professional investors to short overpriced technology stocks, they do not explain our finding that hedge funds held long positions in these stocks.

As a caveat, though, we want to point out that the size of our data set limits us to analyses that are mainly descriptive. In this respect, we view our work more as a clinical study of trading by sophisticated investors during a bubble episode, rather than as an attempt to formally test theories. Nevertheless, it adds valuable empirical evidence to the predominantly theoretical work on bubbles and limits to arbitrage.

Related empirical evidence on the technology bubble is provided by Griffin, Harris, and Topaloglu (2002), who document that on a daily and intraday basis, institutional investors engaged in trend-chasing in Nasdaq 100 stocks. Limits to arbitrage are examined empirically in Mitchell and Pulvino (2001), Mitchell, Pulvino, and Stafford (2002), Baker and Savasoglu (2002), Wurgler and Zhuravskaya (2002), and Lamont and Thaler (2003) in the context of corporate events; Pontiff (1996) looks at closed-end funds. Our paper also contributes to the growing literature on hedge funds. Fung and Hsieh (1997), Ackermann, McEnally, and Ravenscraft (1999), Agarwal and Naik (2000), and Brown and Goetzmann (2003) investigate properties of hedge fund returns and manager skill. Closer in spirit to our work are Brown, Goetzmann, and Park (2000) and Fung and Hsieh (2000). They infer hedge fund holdings indirectly from returns to analyze the role of hedge funds in the Asian crisis and other events.

The rest of our paper is organized as follows. Section I describes our stock holdings data and presents some summary statistics. In Section II, we investigate the extent of hedge fund investments in the technology sector. Section III

\footnotetext{
${ }^{2}$ Other papers on destabilizing speculation include Hart and Kreps (1986) and Brunnermeier and Pedersen (2002), who focus more on higher frequency phenomena, not bubbles, and Allen and Gorton (1993), who show that bad fund managers may have incentives to churn a bubble since they share the profit, but not the loss. Brunnermeier (2001) provides a more comprehensive survey of the literature on bubbles.
} 
provides results on the timing of their exposure at an individual stock level. Section IV concludes.

\section{Data and Sample Characteristics}

\section{A. Defining the Bubble Segment}

In our analysis of hedge fund holdings, we want to focus on stocks that were most likely to be overvalued during the bubble period. To identify candidate firms, we use the ratio of price-to-sales (P/S). Other commonly used price/fundamental ratios such as market-to-book and price-to-earnings suffer from the fact that many companies with rocketing stock prices during our sample period had negative earnings. Based on price-to-earnings ratios, it is then hard to distinguish an overpriced internet company from, say, a distressed "old economy" manufacturing company. For this reason, we prefer the P/S ratio.

Figure 1 graphs value-weighted return indexes of Nasdaq stocks with different P/S ratios from 1998 to 2000 . We use monthly stock returns from CRSP and accounting data from the CRSP/COMPUSTAT-merged database. At the end of each month, we rank stocks based on their P/S ratio using sales figures that are lagged at least 6 months and end-of-month market capitalization. We then sort all stocks into five equally spaced groups based on Nasdaq breakpoints. These portfolios are rebalanced every month. Figure 1 shows that the value of high P/S stocks quadrupled over the course of about 2 years until March 2000. However, more than half of these gains were wiped out by the end of 2000 . Interestingly, this apparently extreme mispricing was not a pervasive phenomenon

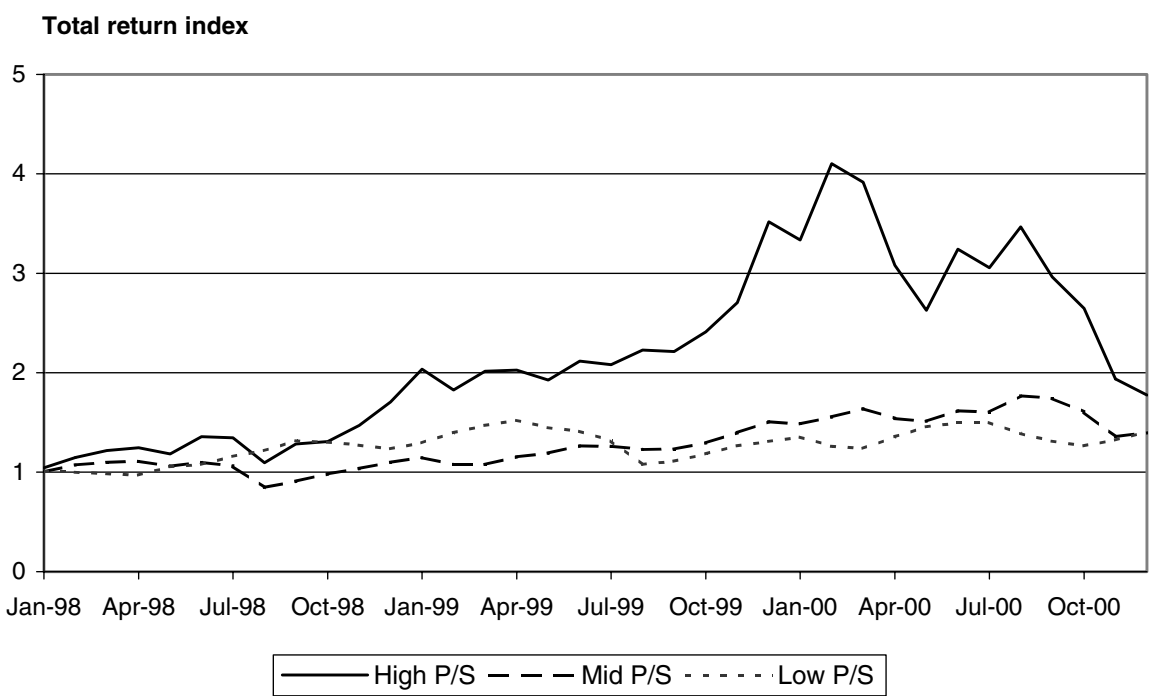

Figure 1. Returns on Nasdaq by price/sales quintile, 1998-2000. At the end of each month, we rank all stocks on Nasdaq by their price/sales ratio and form five portfolios based on quintile breakpoints. Portfolios are rebalanced each month. The figure shows value-weighted indexes of total returns. 
on Nasdaq. The price run-up until March 2000 and the subsequent crash were largely confined to the subset of stocks with the highest $\mathrm{P} / \mathrm{S}$ ratios. Hence, our parsimonious $\mathrm{P} / \mathrm{S}$ grouping appears to do a good job in uncovering the subset of overpriced stocks. In the rest of the paper, we focus mainly on the highest P/S quintile group.

The distribution of $\mathrm{P} / \mathrm{S}$ ratios of internet stocks presented in Lewellen (2003) reveals that about $90 \%$ of them fall into our highest $\mathrm{P} / \mathrm{S}$ quintile. Moreover, the return history of our high $\mathrm{P} / \mathrm{S}$ portfolio in Figure 1 closely mirrors the results presented in Ofek and Richardson (2003) for a sample of internet stocks, which saw price increases of about $1,000 \%$ (equal-weighted) from the start of 1998 to March 2000. In addition to internet stocks, however, our portfolio also contains other technology stocks that were "hot" at the time such as Cisco Systems, Sun Microsystems, and EMC. For simplicity, we therefore refer to the highest P/S group of stocks as the "technology segment."

\section{B. Data on Hedge Fund Holdings}

We use data on stock holdings of hedge fund managers from the CDA/ Spectrum Database maintained by Thomson Financial, which is based on $13 \mathrm{~F}$ filings with the SEC. These data allow us to track positions in individual stocks at a quarterly frequency. The data do not suffer from the selection biases inherent in commercial databases on hedge funds, which are based on information provided voluntarily by hedge funds.

Since 1978, all institutions with more than $\$ 100$ million under discretionary management are required to disclose their holdings in U.S. stocks and a few other securities to the SEC each quarter on form $13 \mathrm{~F}$. This concerns all long positions greater than 10,000 shares or $\$ 200,000$ over which the manager exercises sole or shared investment discretion. The $13 \mathrm{~F}$ filings do not contain information on short positions or derivatives. This is clearly a limitation because the ability to go short is one of the defining characteristics of hedge funds. As we explain in more detail below, we use hedge fund returns data to back out their short positions indirectly. The $13 \mathrm{~F}$ reporting requirements apply regardless of whether an institution is regulated by the SEC or not, and it also applies to foreign institutions if they "use any means or instrumentality of United States interstate commerce in the course of their business."3 Hence, it also applies to hedge funds, provided that their holdings of U.S. stocks exceed the specified thresholds. ${ }^{4}$

We identify candidate hedge fund managers from the first quarter of 1998 issue of the Money Manager Directory published by Hedge Fund Research, Inc. (HFR), a table on hedge fund performance published in the February 19, 1996 issue of Barron's, and a list of hedge fund managers with assets under management in excess of $\$ 500$ million as of December 1995 in Cottier (1997).

\footnotetext{
${ }^{3}$ Section 13(f)(1) of the Securities and Exchange Act of 1934.

${ }^{4}$ The SEC provides detailed information and a 13 F FAQ page on these reporting requirements at www.sec.gov. Gompers and Metrick (2001) provide summary statistics and further information about the CDA/Spectrum database.
} 
The period we investigate in this paper is 1998-2000. We use only sources published prior to the start of this period to ensure that our hedge fund sample is not biased toward ex post more successful funds.

We look up each candidate hedge fund manager by name in the CDA/ Spectrum database. We find records for 71 managers. These are relatively large managers that hold sufficient amounts of U.S. stocks to exceed the $\$ 100$ million reporting threshold. In a second step, we have to deal with the problem that the reporting entity is the institution, not the fund. For example, all holdings of Soros Fund Management are aggregated into one position. It is not revealed which of these pertain to, say, the Quantum Fund, which is one of the funds managed by Soros. This means that we have to discard some managers because hedge fund assets only make up a small part of their aggregated institutional portfolio. For example, Montgomery Asset Management is one of the candidate hedge fund managers in our sample, but its $13 \mathrm{~F}$ filings also include the positions of its large mutual fund business and other nonhedge products. We apply the following selection criteria. For each manager, we check whether the firm is registered as an investment advisor with the SEC. Registration is a prerequisite to conduct nonhedge fund business such as advising mutual funds and pension plans. If the firm is not registered, we include it in our sample. This is the case for most large well-known managers, for example, Soros Fund Management or Tudor Investment Corporation. If the manager is registered, we obtain registration documents (Form ADV). For a registered firm to be eligible for our sample, we require (1) that at least $50 \%$ of its clients are "Other pooled investment vehicles (e.g., hedge funds)" or "High net worth individuals," and (2) that it charges performance-based fees, according to Form ADV. This process leaves us with 53 hedge fund managers. Commonly, each firm manages multiple funds, so our sample comprises stock holdings of probably several hundred different hedge funds.

Having identified our sample of managers, we extract their quarterly holdings from the first quarter of 1998 to the last quarter of 2000 . We take care to adjust properly for the splits' problem pointed out by Gompers and Metrick (2001), which causes reports filed after the 45-day deadline set by the SEC to be distorted by stock splits. In very few cases the filing is more than 3 months delayed. We discard these observations. For 16 manager-quarter observations in our hedge fund sample, there is an intermediate missing report. In this case, we assume that (split-adjusted) holdings remained unchanged from the quarter preceding the missing report.

\section{Summary Statistics}

Table I provides some summary statistics on our sample. As this paper is the first piece of research that looks at hedge fund stock holdings, the information in Table I is noteworthy. The first column shows the number of managers for which we have a valid report. All of the 53 managers in our sample existed in the first quarter of 1998 . The reason why some do not have $13 \mathrm{~F}$ filings in the early quarters of the sample is that they did not hold a sufficient amount of U.S. 
Table I

\section{Summary Statistics}

The total sample comprises 53 hedge fund managers that existed prior to 1998 for which we have CDA/Spectrum data, and that satisfy the inclusion criteria described in the text. The number of managers in the first column refers to those with a valid $13 \mathrm{~F}$ filing in the given quarter. Stock holdings per manager denotes the sum of the market value of all stocks held by the manager at the end of the quarter. Portfolio turnover is defined as the minimum of the absolute values of buys and sells during a quarter $t$ divided by total holdings, where buys, sells, and holdings are measured with end-of-quarter $t-1$ prices. Means, medians, and cross-sectional semi-interquartile ranges (s.i.q.r., one-half the difference between the $75^{\text {th }}$ and $25^{\text {th }}$ percentile) for portfolio turnover are annualized.

\begin{tabular}{|c|c|c|c|c|c|c|c|c|c|c|c|c|}
\hline \multirow[b]{2}{*}{ Year } & \multirow[b]{2}{*}{ Qtr. } & \multirow[b]{2}{*}{$\begin{array}{l}\text { Number } \\
\text { of Mgrs. }\end{array}$} & \multicolumn{3}{|c|}{$\begin{array}{l}\text { Stock Holdings per } \\
\text { Manager }\end{array}$} & \multicolumn{3}{|c|}{$\begin{array}{l}\text { Number of Stocks } \\
\text { per Manager }\end{array}$} & \multicolumn{3}{|c|}{ Portfolio Turnover } & \multirow{2}{*}{$\begin{array}{c}\begin{array}{c}\text { Stock } \\
\text { Holdings }\end{array} \\
\begin{array}{c}\text { Aggregate } \\
(\$ \text { mill })\end{array}\end{array}$} \\
\hline & & & $\begin{array}{l}\text { Mean } \\
(\$ \text { mill })\end{array}$ & $\begin{array}{l}\text { Median } \\
(\$ \text { mill })\end{array}$ & $\begin{array}{l}\text { S.i.q.r. } \\
(\$ \text { mill })\end{array}$ & Mean & Median & S.i.q.r. & $\begin{array}{l}\text { Mean } \\
\text { (ann.) }\end{array}$ & $\begin{array}{l}\text { Median } \\
\text { (ann.) }\end{array}$ & $\begin{array}{l}\text { S.i.q.r. } \\
\text { (ann.) }\end{array}$ & \\
\hline \multirow[t]{4}{*}{1998} & 1 & 35 & 1,280 & 295 & 755 & 150 & 56 & 77 & & & & 44,794 \\
\hline & 2 & 42 & 1,053 & 231 & 445 & 113 & 50 & 49 & 1.02 & 0.94 & 0.34 & 44,234 \\
\hline & 3 & 42 & 728 & 145 & 364 & 71 & 44 & 30 & 0.83 & 0.57 & 0.40 & 30,594 \\
\hline & 4 & 41 & 925 & 178 & 417 & 66 & 39 & 36 & 1.16 & 1.05 & 0.58 & 37,912 \\
\hline \multirow[t]{4}{*}{1999} & 1 & 39 & 1,070 & 216 & 538 & 74 & 47 & 39 & 0.98 & 0.84 & 0.55 & 41,742 \\
\hline & 2 & 42 & 995 & 211 & 382 & 75 & 48 & 38 & 1.12 & 1.12 & 0.50 & 41,807 \\
\hline & 3 & 43 & 927 & 244 & 426 & 69 & 37 & 42 & 1.28 & 1.32 & 0.46 & 39,879 \\
\hline & 4 & 44 & 1,136 & 270 & 615 & 83 & 46 & 41 & 1.02 & 0.95 & 0.51 & 49,981 \\
\hline \multirow[t]{4}{*}{2000} & 1 & 43 & 1,138 & 316 & 792 & 85 & 39 & 49 & 1.33 & 1.12 & 0.71 & 48,933 \\
\hline & 2 & 44 & 772 & 246 & 383 & 67 & 37 & 41 & 1.19 & 0.99 & 0.75 & 33,988 \\
\hline & 3 & 45 & 861 & 269 & 413 & 80 & 37 & 34 & 1.21 & 1.22 & 0.63 & 38,747 \\
\hline & 4 & 48 & 812 & 190 & 427 & 100 & 45 & 37 & 1.06 & 0.77 & 0.70 & 38,989 \\
\hline
\end{tabular}


stocks to cross the $\$ 100$ million reporting threshold. They may also disappear for the same reason.

The second set of columns contains statistics on the distribution of stock holdings across managers. For these statistics, we sum up the total market value of all stock holdings for each manager. Compared with mutual fund managers, the mean holding of about $\$ 1$ billion is small..$^{5}$ The median is much lower, which indicates that the distribution is skewed, with a few large managers accounting for the bulk of stock holdings. The five managers with the largest holdings in the first quarter of 1998-Soros Fund Management, Tiger Management, Omega Advisors, Husic Capital Management, and Zweig Di-Menna Associates-account for about $60 \%$ of total stock holdings. Aggregate stock holdings, reported in the last column, fluctuate between $\$ 31$ and $\$ 50$ billion. For comparison, TASS and MAR/Hedge, two of the major data providers in this area, estimate the total assets under management in the hedge fund industry at the beginning of 2000 to be between $\$ 150$ and $\$ 200$ billion. This suggests that our data capture a significant part of total hedge fund stock holdings.

The third set of columns shows the number of stocks held by the hedge fund managers in our sample. With the mean at about 100 stocks and the median around 50, these numbers show that hedge fund holdings are fairly concentrated, which is somewhat typical for active managers who make deliberate bets on a relatively small group of stocks or single segments of the market.

In the fourth set of columns, we report the approximate portfolio turnover. We follow the CRSP mutual funds database and Wermers (2000) and define turnover as the minimum of the absolute values of buys and sells of a manager in a given quarter divided by her total stock holdings. This definition of turnover captures trading unrelated to in- or outflows. Since we calculate it from quarterly holdings snapshots, it is understated. Even so, this turnover measure provides an important diagnostic. If hedge funds only did high-frequency trading, moving in and out of the same stock within a quarter, our quarterly holdings data would provide little information about trading patterns. However, as the table shows, quarterly turnover is about $25 \%$ (100\% annualized). This is somewhat higher than turnover for the average mutual fund, which Wermers (2000) found to be $72.8 \%$ (annualized) in 1994, but it still indicates that a substantial part of holdings survives from one quarter to the next. This suggests that there is some low-frequency component in hedge fund strategies that is captured well by quarterly holdings snapshots. It is precisely this low-frequency component that we are most interested in, that is, the overall allocation to a large market segment, rather than high-frequency trades in individual stocks.

We also note that the hedge funds in our sample hold only around $0.3 \%$ of outstanding aggregate equity. This is not surprising, as aggregate stock holdings of hedge funds in our sample (about $\$ 30$ to $\$ 50$ billion) are dwarfed by holdings of other institutional investors such as mutual funds and pension funds. We therefore want to emphasize that our aim is not to draw conclusions about

\footnotetext{
${ }^{5}$ Gompers and Metrick (2001) report that the average mutual fund institution (that usually comprises multiple funds) in the Spectrum database in 1996 managed in excess of $\$ 10$ billion.
} 
causal links between changes in hedge fund holdings and price changes. Our interest in this paper centers on understanding the trading behavior of sophisticated and presumably close-to-rational investors when faced with a bubble, not on price impact.

\section{Did Hedge Funds Trade against the Bubble?}

The first point we want to establish is whether hedge funds were attacking the bubble in technology stocks-by selling their holdings in this segment, or even by going short_-or whether hedge funds were riding the bubble. According to the efficient markets view, rational investors should short assets they know to be overpriced. By contrast, the $\mathrm{AB}$ (2003) model shows that they may want to ride bubbles for a while. For the time being, our working assumption is that hedge fund managers were aware of the bubble in technology stocks, for example, because they performed the back-of-the-envelope calculation of Ofek and Richardson (2002) we mentioned in the beginning. Of course, we also need to entertain the possibility that they failed to spot the bubble. We defer this issue until the next section. We start by analyzing the weight of technology stocks in hedge fund stock portfolios. To assess the effect of hedge fund short positions and derivatives, we also look at returns of hedge funds.

\section{A. Exposure to Technology Stocks: Portfolio Weights}

At the end of each quarter, we sum up all holdings retrieved from $13 \mathrm{~F}$ reports across all managers to compile the aggregate hedge fund portfolio. As explained above, we define the technology segment as the high price/sales quintile of the Nasdaq, as this is a parsimonious way of capturing the most overpriced stocks. We compute the total market value of hedge fund holdings in the Nasdaq high P/S segment and relate them to the total market value of their entire stock holdings. For comparison, we also compute the weight of Nasdaq high P/S stocks in the market portfolio of all stocks on CRSP. Figure 2 shows the evolution of these weights over time. The columns show the weight of technology stocks in the aggregate hedge fund portfolio. The line represents the corresponding weights in the market portfolio. As relative price movements change portfolio weights over time, the hedge fund portfolio weights should be compared to market portfolio weights, rather than be judged by their absolute level.

The first striking fact in this figure is that hedge funds generally overweighted technology stocks in their portfolios. For example, when the Nasdaq peaked in March 2000, hedge funds had devoted 31\% of their stock portfolio to this segment. For comparison, these stocks only commanded a weight of $21 \%$ in the market portfolio at that time. The evolution of these weights over time also reveals some interesting patterns. Following the buildup of an overweighted position in late 1998, hedge funds subsequently reduced their exposure. This 


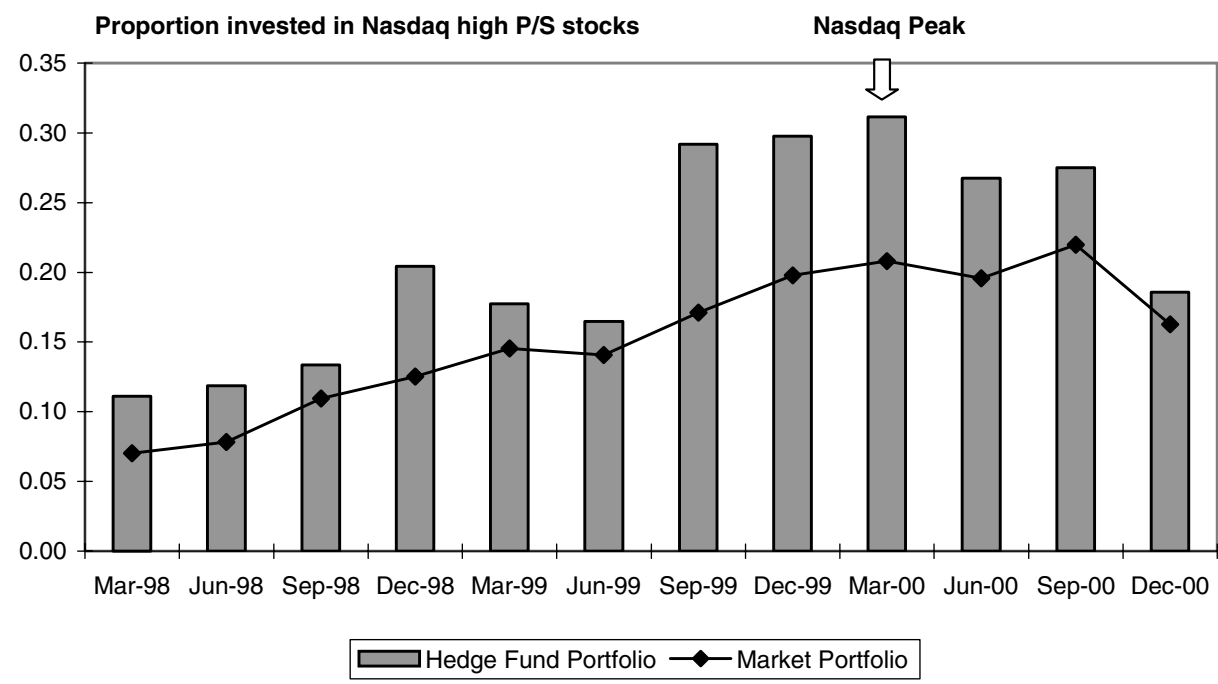

Figure 2. Weight of Nasdaq technology stocks (high $P / S$ ) in aggregate hedge fund portfolio versus weight in market portfolio. At the end of each quarter, we compute the weight, in terms of market value, of high $\mathrm{P} / \mathrm{S}$ quintile Nasdaq stocks in the overall stock portfolio of hedge funds, given their reported holdings on form $13 \mathrm{~F}$. For comparison, we also report the value-weight of high P/S stocks in the market portfolio (all stocks on CRSP).

is at least somewhat consistent with the remark of Soros Fund Managements' then-chief investment officer Stanley Druckenmiller that they were "calling the bursting of the internet bubble" in spring $1999 .{ }^{6}$ As it turned out, this call was too early. The bubble did not burst yet. Then, within just one quarter, hedge funds increased the weight of technology stocks from $16 \%$ to $29 \%$ in September 1999. The market portfolio weights only changed from $14 \%$ to $17 \%$. Interestingly, this increase occurred just before the final price run-up of technology stocks. From the end of September 1999 to February 2000, the high P/S segment of the Nasdaq gained almost $100 \%$ (see Figure 1). Relative to market portfolio weights, September 1999 marks the peak of technology exposure of hedge funds. The gap narrows gradually over the subsequent quarters. At the end of 2000, the hedge fund portfolio weight is very close to the market portfolio weight.

Could this tilt toward technology stocks in hedge fund portfolios simply be the result of preferential share allocations in initial public offerings (IPO)? Recently, there have been allegations that hedge funds and other institutional investors received favorable allocations of shares in "hot" IPOs, that is, stocks that would rise substantially on their first day of trading-in exchange for providing kickbacks to investment banks in the form of inflated trading commissions

\footnotetext{
6 "After having made money in the internet pre-January 1999, on the long side, we were too early in calling the bursting of the internet bubble." (Pacelle (1999)).
} 
(see Ljungqvist and Wilhelm (2002), Ritter and Welch (2002)). One of the alleged practices involves "flipping," which means selling allocated shares on the first day of trading to capture the large initial return. Since we look at quarterly holdings snapshots, most of these flipped shares would not appear in our data. Hence, flipping activity cannot cloud our holdings analysis. However, IPO shares held over longer periods would be captured. To shed some light on this, we have split hedge fund holdings at each quarter-end into shares that newly appeared on CRSP (our proxy for the time of the IPO) over the previous 12 months and the residual sample of non-IPO shares. For both samples, we find that hedge fund portfolios were tilted toward technology stocks in a similar manner. In terms of hedge fund investments, newly listed technology stocks therefore do not seem to be substantially different from those with a longer listing history.

Overall, this preliminary analysis of long positions suggests that hedge funds did not engage in a persistent attack on the technology bubble. In contrast, it seems that at least until late 1999, their trading mostly supported, rather than undermined the bubble. Hedge funds were riding the bubble, not fighting it. From an efficient markets perspective, these results are puzzling. Why would some of the most sophisticated investors in the market hold these overpriced technology stocks? And why would they devote a larger share of their portfolio to these stocks than other investors?

Apart from our working assumption that hedge fund managers knew about the bubble, this initial analysis leaves open two further questions. First, there is certainly a possibility that hedge funds took short positions in technology stocks. In this case, looking only at long positions would clearly be misleading. We deal with this issue in the next subsection. Second, one might suspect that hedge funds may have reacted to the bubble by pulling out of stocks altogether, not just technology stocks - a move that would not leave a trace in the portfolio weights in Figure 2. However, the aggregate hedge fund stock holdings shown in the summary statistics in Table I do not suggest that such a pullout took place.

\section{B. Exposure to Technology Stocks: Return Regressions}

We now back out short positions from hedge fund returns. Similar in spirit to Sharpe (1992), we assume that hedge fund returns can be written as the weighted average of the returns on a few asset classes plus some idiosyncratic return. Given our short sample period, we restrict ourselves to two asset classes: the market portfolio with return $R_{M}$ and a portfolio of technology stocks with return $R_{T}$. Without further loss of generality, we can then think of the asset allocation decision of hedge fund managers as involving two steps. First, allocate a fraction $b$ (by value) of the total portfolio to the market portfolio. For a long-only fund without leverage, $b$ is likely to be somewhere around one. For a market-neutral fund, which would offset long exposure to stocks with short positions, it would be around zero. Second, to achieve the desired exposure to technology stocks, reallocate a fraction $g$ of the total portfolio value from the 
initial market investment to technology stocks. The return of this hedge fund can then be written as

$$
R_{t}=(b-g) R_{M t}+g R_{T t}+e_{t},
$$

where $e_{t}$ is the idiosyncratic return.

In Figure 2 above, we compare the ratio of hedge fund long positions in technology holdings to overall long stock holdings with $m_{T}$, the weight of technology stocks in the market portfolio. Here we want to perform a similar comparison, but using net investment figures, which take into account short sales. In our simple model, the net investment in technology stocks as a proportion of the total portfolio is $(b-g) m_{T}+g$. The net investment in stocks overall is $b$. Taking the ratio of the two and rearranging terms we get

$$
w_{T}=m_{T}+\frac{g}{b}\left(1-m_{T}\right) .
$$

For a long-only fund tracking the market portfolio, we would have $b=1$ and $g=0$, and therefore $w_{T}=m_{T}$. For a market-neutral fund $(b=0)$ with some long exposure to technology stocks $(g>0), w_{T}$ would tend to infinity because the net investment in stocks in the denominator is zero. If $b<0$, the meaning of $w_{T}$ is different. ${ }^{7}$ Therefore, we compute it only for funds that have $b>0$. To estimate $w_{T}$, we can recover the parameters $b$ and $g$ in (1) from the following OLS regression:

$$
R_{t}=\alpha+\beta R_{M t}+\gamma\left(R_{T t}-R_{M t}\right)+\varepsilon_{t} .
$$

Given our assumptions, it is easy to show that $\beta=b$ and $\gamma=g$. For ease of reference, we denote the second factor, $R_{T t}-R_{M t}$, the $T E C H$ factor.

This simple factor model is certainly not a perfect solution. First, if hedge funds are invested in some other omitted asset classes, whose returns are correlated with $R_{T}$ or $R_{M}$, our estimates would be biased. However, it is not obvious which types of assets would be correlated in this way. Second, some hedge funds may also apply dynamic trading strategies, which generate nonlinear exposure to asset class factors, implying that a linear model is misspecified (Fung and Hsieh (1997), Agarwal and Naik (2000)). We performed an informal check of scatterplots and did not find much nonlinearity in our sample of hedge fund returns. Overall, we believe that our simple model provides a reasonably accurate perspective on the direction of hedge funds' exposure to the technology segment.

We run the regression in equation (3) with monthly returns over the sample period April 1998 to December 2000. Our hedge fund returns data come from several sources. All returns are net-of-fees. For our first sample, we identify the

\footnotetext{
${ }^{7}$ For funds with overall short exposure $(b<0)$, a short exposure to tech stocks $(g<0)$ would result in a positive $w_{T}$. This could be mitigated by using the absolute value of $b$ in equation (2). However, in that case, higher overall short exposure $(b \ll 0)$ would raise $w_{T}$ toward zero even though the portfolio now contains more short positions in tech stocks than before. This makes $w_{T}$ unsuitable for comparing technology exposure across funds with positive and negative $b$.
} 
five largest managers in terms of stock holdings at the beginning of our sample period. We were able to obtain performance data for one fund per manager, and we construct an equal-weighted index of their returns, denoted Large. ${ }^{8}$ Our second sample comprises hedge fund style indexes compiled by Hedge Fund Research, Inc. (HFR). HFR groups hedge funds according to their investment style and calculates performance indexes for each category. The HFR database includes nonsurviving funds (see Agarwal and Naik (2000)). We select those styles that are likely to have significant exposure to equities (we discard fixed income styles, for example). Third, we also calculate a monthly return series on a long-only "copycat" fund, denoted $13 \mathrm{~F}$. We construct it by adding up quarterly hedge fund holdings-as they appear in our $13 \mathrm{~F}$ filings data-across all hedge funds. We know the technology exposure of this portfolio from Figure 2, and hence it allows us to check whether our results make sense.

Table II presents our estimates. Panel A reports results for the index of large manager funds (Large). The estimated coefficients show that, on average, the largest hedge fund managers in our sample had positive exposure to the TECH factor (0.17). The coefficient on the TECH factor is significant at conventional significance levels ( $t$-statistic of 2.51). This translates into an implied technology weight of $49 \%$ (standard error of $8 \%$ ), reported in the last column. This is even higher than the weight we found in Figure 2, which is about $21 \%$ on average. This reflects the fact that short positions can offset not only technology exposure, but also market exposure. Short positions of the latter kind can increase the relative weight of technology stocks (they lower the denominator in $w_{T}$ ). In fact, the relatively modest estimate of 0.42 for market exposure suggests that some short positions were used to offset market exposure.

Panel B repeats the same exercise for different HFR style categories. Since our sample of hedge funds and the HFR universe are only partly overlapping, this analysis also provides useful additional information. A first glance at the results shows that coefficients on the market factor have the signs and magnitudes we would expect given the style categories. Equity-market neutral funds have $\beta \approx 0$. Equity nonhedge funds, which focus on long positions, have a market beta not too far from one. Short-selling specialists, on the other hand, have $\beta=-1$. With respect to loadings on the TECH factor and the implied technology weight, we find that equity nonhedge and equity-hedge funds show the same patterns we observed in Panel A. Both have implied technology weights in excess of $30 \%$. For market-timing funds, macro funds, and equity market-neutral funds, the $w_{T}$ point estimate is above $30 \%$, too, but it is more imprecisely estimated. Low overall exposure to stocks $(\beta)$ makes it hard to estimate the weight. Not surprisingly, sector technology funds have the highest $w_{T}$, an artifact of their sector focus. More interestingly, short-selling specialists are the only ones with negative exposure to the TECH factor. For every percent the Nasdaq high

\footnotetext{
${ }^{8}$ The data source is a merged database of MAR, TASS, and HFR. We thank Narayan Naik and Subhra Tripathy at the London Business School Centre for Hedge Fund Research and Education for providing these data. Unfortunately, agreements with data vendors prevent us from disclosing the performance of individual hedge funds.
} 


\section{Table II}

\section{Exposure of Hedge Funds to the Technology Segment: Two-Factor Return Regressions}

This table reports the results of time-series regressions of monthly hedge fund return indexes on $R_{M}$, the CRSP value-weighted NYSE/AMEX/Nasdaq market index, and $R_{T}-R_{M}$, the return on the Nasdaq high $\mathrm{P} / \mathrm{S}$ portfolio minus the market return (the TECH factor).

$$
R_{t}=\alpha+\beta R_{M t}+\gamma\left(R_{T t}-R_{M t}\right)+\varepsilon_{t}
$$

The sample period is from April 1998 to December 2000. The $t$-statistics for coefficient estimates are in parentheses. We use $\beta$ and $\gamma$ estimates to compute $w_{T}$, the implied ratio of net investments in technology stocks to net investments in stocks overall, with delta-method standard errors (see, e.g., Campbell, Lo, and MacKinlay, 1997, p. 540) reported in brackets. The dependent variable in Panel A is an equal-weighted index of five funds managed by the five largest managers in our sample. In Panel B left-hand variables are returns on HFR style indexes, classified by HFR as follows: Equity Hedge funds invest in core holdings of long equities, hedged at all times with short sales of stocks and/or stock index options. Equity Market Neutral investing seeks to profit by exploiting pricing inefficiencies between related equity securities, neutralizing exposure to market risk by combining long and short positions. Equity NonHedge funds are predominately long equities, although they have the ability to hedge with short sales of stocks and/or stock index options. Macro involves investing by making leveraged bets on anticipated price movements of stock markets, interest rates, foreign exchange, and physical commodities. Market Timing involves switching into investmentsmostly mutual funds and money markets - that appear to be beginning an uptrend and switching out of investments that appear to be starting a downtrend. Short Sellers specialize in short-selling securities. Sector Technology funds emphasize investment in securities of the technology arena. In Panel $\mathrm{C}$, the dependent variable is the monthly return on the aggregate long positions of hedge funds, as reported in their 13F filings and analyzed in Figure 2.

\begin{tabular}{|c|c|c|c|c|}
\hline \multirow[b]{2}{*}{ Index } & \multicolumn{2}{|c|}{ Factor Loadings } & \multirow[b]{2}{*}{ Adj. $R^{2}$} & \multirow{2}{*}{$\frac{\text { Implied Tech-Weight }}{w_{T}}$} \\
\hline & $\beta$ & $\gamma$ & & \\
\hline \multicolumn{5}{|c|}{ Panel A: Equal-weighted Index of Largest Funds in Our Sample (1998-2000) } \\
\hline Large & $\begin{array}{c}0.42 \\
(3.51)\end{array}$ & $\begin{array}{c}0.17 \\
(2.51)\end{array}$ & 0.56 & $\begin{array}{c}0.49 \\
(0.08)\end{array}$ \\
\hline \multicolumn{5}{|c|}{ Panel B: HFR Hedge Fund Style Indexes (1998-2000) } \\
\hline Equity-hedge & $\begin{array}{c}0.45 \\
(6.36)\end{array}$ & $\begin{array}{c}0.15 \\
(3.92)\end{array}$ & 0.80 & $\begin{array}{c}0.44 \\
(0.04)\end{array}$ \\
\hline Equity nonhedge & $\begin{array}{c}0.74 \\
(9.07)\end{array}$ & $\begin{array}{c}0.16 \\
(3.57)\end{array}$ & 0.86 & $\begin{array}{c}0.34 \\
(0.03)\end{array}$ \\
\hline Equity market-neutral & $\begin{array}{c}0.07 \\
(1.54)\end{array}$ & $\begin{array}{c}0.01 \\
(0.53)\end{array}$ & 0.10 & $\begin{array}{c}0.32 \\
(0.15)\end{array}$ \\
\hline Market timing & $\begin{array}{c}0.25 \\
(3.45)\end{array}$ & $\begin{array}{c}0.07 \\
(1.67)\end{array}$ & 0.48 & $\begin{array}{c}0.38 \\
(0.08)\end{array}$ \\
\hline Short-selling specialists & $\begin{array}{l}-1.00 \\
(-5.93)\end{array}$ & $\begin{array}{l}-0.43 \\
(-4.57)\end{array}$ & 0.80 & \\
\hline Macro & $\begin{array}{c}0.13 \\
(1.84)\end{array}$ & $\begin{array}{c}0.09 \\
(2.13)\end{array}$ & 0.34 & $\begin{array}{l}0.70 \\
(0.21)\end{array}$ \\
\hline Sector technology & $\begin{array}{c}0.71 \\
(5.29)\end{array}$ & $\begin{array}{c}0.57 \\
(7.62)\end{array}$ & 0.86 & $\begin{array}{c}0.84 \\
(0.08)\end{array}$ \\
\hline
\end{tabular}

Panel C: Aggregate Long Portfolio (As in Figure 2)

\begin{tabular}{ccccc}
\hline $13 \mathrm{~F}$ & 1.13 & 0.29 & 0.89 & 0.37 \\
& $(9.97)$ & $(4.49)$ & & $(0.03)$
\end{tabular}


$\mathrm{P} / \mathrm{S}$ segment return underperformed the market, they earned $0.44 \%$. Since $w_{T}$ has a different meaning when $\beta<0$, we do not report it for short-selling specialists. The $\gamma$ estimates indicate, however, that they had short exposure to the technology segment over and above the exposure obtained through their short positions against the market.

Panel $\mathrm{C}$ shows the results for the long positions portfolio 13F. If our simple two-asset class model held perfectly, we would expect $w_{T}$ to be equal to the average weight of $21 \%$ from Figure 2. As the table shows it is $37 \%$ instead. The reason is that hedge funds not only had overweighted exposure to the fifth $\mathrm{P} / \mathrm{S}$ quintile, which is analyzed in Figure 2, but also to the fourth and third, whose returns are highly correlated with the returns on the fifth quintile. This exposure is picked up by the TECH factor, too.

In summary, Table II clearly shows that accounting for short positions strengthens rather than weakens our finding that hedge funds had strong long exposure to technology stocks. Short positions were used by many hedge fundsbut mainly to offset market exposure, not technology exposure. Of course, these regressions only yield the average exposure over the entire sample period. We would also like to know whether the time pattern of exposures estimated from returns matches the pattern we found in holdings. We have to entertain the possibility that short exposure of hedge funds was concentrated in a short period, for example during 1999, which might not show up in the full-period average.

To address this point, we estimate the factor regression (3) with time-varying coefficients, using the Kalman filter. Specifically, we consider the following model:

$$
R_{t}=\bar{\alpha}+\xi_{1 t}+\left(\bar{\beta}+\xi_{2 t}\right) R_{M t}+\left(\bar{\gamma}+\xi_{3 t}\right)\left(R_{T t}-R_{M t}\right)+\varepsilon_{t} .
$$

Stochastic variation in regression coefficients is captured by the unobserved state vector $\xi_{t}$, for which we assume the following dynamics

$$
\left(\begin{array}{l}
\xi_{1 t+1} \\
\xi_{2 t+1} \\
\xi_{3 t+1}
\end{array}\right)=\left(\begin{array}{lll}
0 & 0 & 0 \\
0 & \phi & 0 \\
0 & 0 & \phi
\end{array}\right)\left(\begin{array}{l}
\xi_{1 t} \\
\xi_{2 t} \\
\xi_{3 t}
\end{array}\right)+\left(\begin{array}{l}
\eta_{1 t+1} \\
\eta_{2 t+1} \\
\eta_{3 t+1}
\end{array}\right),
$$

where the disturbances $\eta_{t}$ and $\varepsilon_{t}$ are normally distributed and mutually uncorrelated conditional on $\left\{R_{M 1}, \ldots, R_{M t}, R_{T 1}, \ldots, R_{T t}, R_{1}, \ldots, R_{t-1}\right\}$, and uncorrelated over time. We assume that shocks to alphas are completely transitory, and shocks to factor loadings are persistent, with both factors sharing the same persistence parameter $\phi$. These assumptions are somewhat restrictive, but necessary to keep the number of free parameters low enough for our relatively short sample. We run Kalman filter iterations to find the $M L$ parameter estimates for this system. Based on these $M L$ estimates, the Kalman filter provides forecasts of $\xi_{t}$ conditional on $\left\{R_{M 1}, \ldots, R_{M t}, R_{T 1}, \ldots, R_{T t}, R_{1}, \ldots, R_{t-1}\right\}$. In a second step, we employ a smoothing algorithm (see Hamilton (1994) for details). Intuitively, smoothing uses all the available sample information $(t=1, \ldots, T)$ to infer $\xi_{t}$, and hence factor loadings and the intercept at each point in time. 


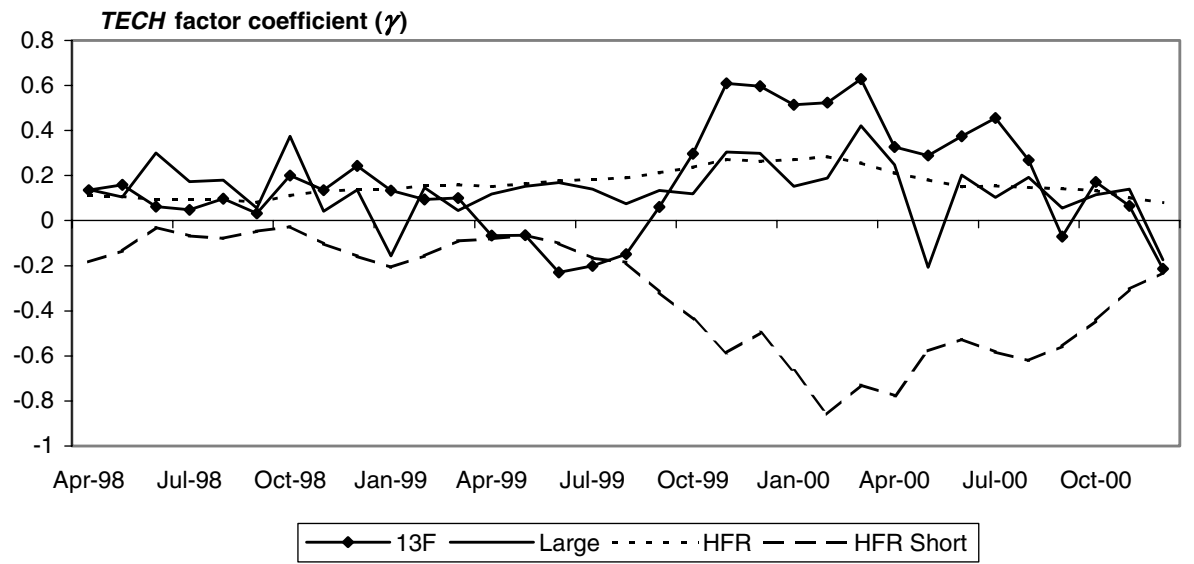

Figure 3. Exposure of hedge funds to the technology segment: Smoothed Kalman filter estimates. Time-series regressions of monthly hedge fund return indexes on $R_{M}$, the CRSP valueweighted NYSE/AMEX/Nasdaq market index, and the TECH factor, which is the Nasdaq high P/S portfolio return $R_{T}$ minus the market return, are run like in Table II, but allowing for stochastically time-varying regression slopes, estimated via Kalman filtering and smoothing. Dependent variables are $13 \mathrm{~F}$, the return on the portfolio of aggregate long holdings of all hedge funds from our $13 \mathrm{~F}$ filings data; Large, an equal-weighted average of returns on five funds managed by the five largest managers in our sample; and HFR, which is an equal-weighted average across all HFR style indexes examined in Table II, with the exception of short-selling specialists (HFR Short), which are considered separately. The figure shows the estimated coefficients $(\gamma)$ on the TECH factor.

Figure 3 presents our estimates. Market betas turn out to be fairly constant over time for all of our hedge fund groups, close to the means reported in Table II, so we focus on TECH factor loadings. In the interest of parsimony, we group all HFR styles except short-selling specialists into one equal-weighted index, denoted HFR. Short-selling specialists (HFR Short) are considered separately. Large and $13 \mathrm{~F}$ are the same as before in Table II. The $13 \mathrm{~F}$ series is again useful to check the methodology because we know from Figure 2 how the time variation in exposure should look. As Figure 3 shows, its time-varying loading on the TECH factor closely mirrors: Figure 2 technology exposure was highest relative to the market portfolio around the end of 1999, and it decayed toward the end of 2000. Evidently, the Kalman filter does a good job of capturing the time variation in exposure to the technology segment.

Turning to the results of main interest, the graphs for HFR and Large show that factor exposures estimated from hedge fund returns are close to the factor exposures of our long-only portfolio (13F). They indicate that these funds overweighted technology stocks during almost the entire sample period, with peaks in early 2000. This again ties in well with our findings in Figure 2. The exposure of short-selling specialists (HFR Short) is quite different, however, and shows remarkable timing. Until July 1999, their exposure is well described as being short the market portfolio (see Table II), without much directional bias 
concerning the technology segment. Yet, after this date, they started going short on technology stocks. By the time of the Nasdaq peak in March 2000, they already had a strong short exposure. Nevertheless, the essence is that even these funds, which do not do much other than shorting, did not attack the bubble before it was close to bursting. ${ }^{9}$

Overall, the factor regression results confirm that our long positions data do not paint a misleading picture of hedge funds' exposure to technology stocks. In the remainder of the paper, we therefore return to our holdings data to investigate questions that cannot be addressed with returns data, in particular, the trades of individual hedge funds in individual stocks.

\section{Portfolio Holdings of Individual Managers and Fund Flows}

So far we have couched our analysis in terms of the aggregate hedge fund portfolio. However, different managers may have taken different approaches in dealing with the bubble. Apart from revealing some aspects of the trading strategies of some highly sophisticated market participants, such differences in strategies would also be interesting because they may have resulted in differences in fund flows. Shleifer and Vishny (1997) argue that arbitrage is limited because investors would withdraw capital from portfolio managers that lose money, even if these losses are simply the result of a temporary deepening of mispricing. We do not have sufficient data for a full-scale cross-sectional analysis, but we do have fund flows data to illustrate two prominent contrasting cases: Soros Fund Management and Tiger Management.

Figure 4a examines the portfolio weights of the five managers with the largest stock holdings at the start of 1998. As we reported earlier, these five managers account for about $60 \%$ of aggregate stock holdings in our sample. Similar to the analysis in Figure 2, in Figure 4a, we compute the weight of high P/S Nasdaq stocks-this time for individual funds-and compare them to the corresponding weights in the market portfolio. The results are consistent with anecdotal evidence about these managers' strategies. Tiger Management, for example, a well-known value-manager, invested only little in technology stocks. In 1999, Tiger eliminated virtually all investments in this segment. This is consistent with the widely reported refusal of Julian Robertson, manager of the Tiger Fund, to buy into the internet bubble. The weights of Soros Fund Management were quite similar to Tiger at the end of 1998, but the firms took radically different paths in 1999. During the third quarter of 1999, Soros increased the proportion invested in the technology segment from less than $20 \%$ to about $60 \%$. Zweig-DiMenna and Husic also decided to overweight technology stocks. Omega, in contrast, structured the portfolio more along the lines of Tiger.

\footnotetext{
${ }^{9}$ Note also that short-selling specialists are a rare species. Agarwal and Naik (2000) report that the HFR short-seller category contained 12 funds in December 1998 (compared with 223 for Equity-Hedge or 746 for the entire HFR sample). According to the Third Quarter of 2000 Asset Flows Report provided by TASS, short-sellers account for only $0.3 \%$ of all hedge fund assets.
} 


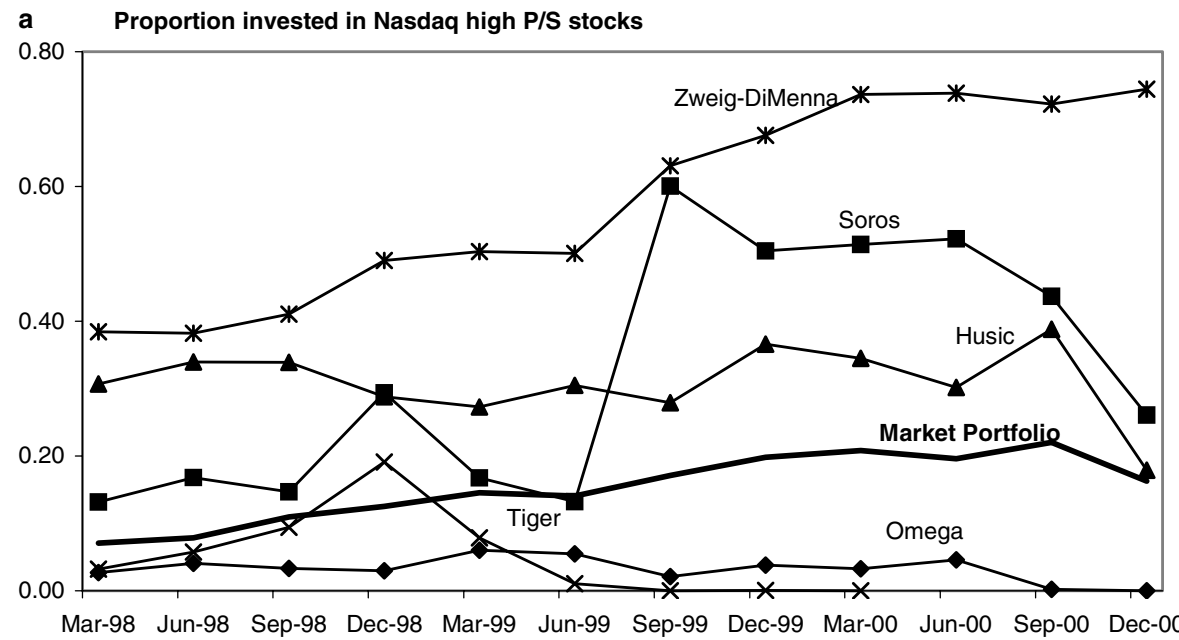

b Fund flows as proportion of assets under management

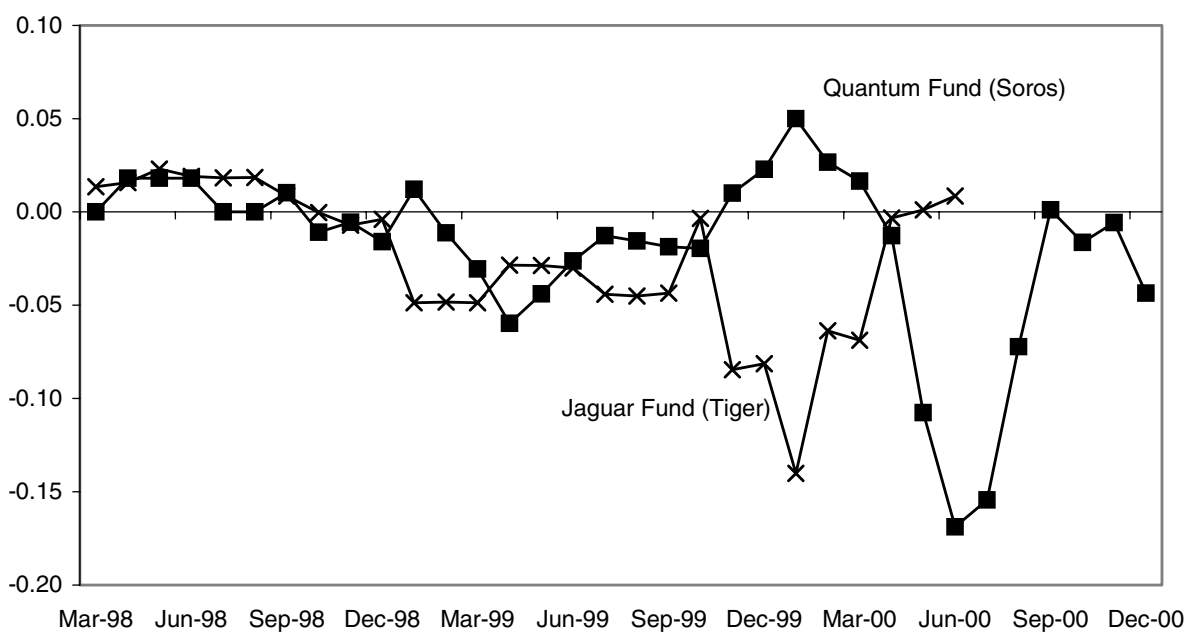

Figure 4. Investment in technology stocks and fund flows for individual hedge fund managers. (a) We compute the end-of-quarter weight, in terms of market value, of high $\mathrm{P} / \mathrm{S}$ quintile Nasdaq stocks in the overall stock portfolio of hedge funds, given their reported holdings on form 13F. For comparison, we also report the value-weight of high P/S stocks in the market portfolio (all stocks on CRSP). Results are shown for the five managers with the largest overall stock holdings in March 1998. (b) Shows a 3-month moving average of monthly fund flows backed out from monthly time-series of assets under management and fund performance for the Quantum Fund (Soros Fund Management) and the Jaguar Fund (Tiger Management).

To examine the relationship to flows, we back out fund flows from data on assets under management and fund performance. Unfortunately, our data on assets under management is incomplete. Among the funds managed by the five managers in Figure 4a, we are able to calculate complete monthly histories of 
flows only for the Quantum Fund (Soros Fund Management) and the Jaguar Fund (Tiger Management), which is an offshore version of the Tiger Fund. Other funds are either closed (no flows at all) or the data are updated only very irregularly.

Figure 4b shows 3-month moving averages of fund flows for Quantum and Jaguar in percent of assets under management. Flow patterns for both funds were relatively similar in 1998 . However, this changed dramatically when their technology exposure diverged in mid-1999. Soros' subsequent performance benefited from the final run-up of the bubble until March 2000, and the Quantum Fund attracted new capital. In contrast, the capital base of the Jaguar Fund was eroded by strong outflows. In October 1999, Tiger Management increased the redemption period for investors from 3 to 6 months in order to curb outflows (Bloomberg News (1999)). Nevertheless, in the final quarter of 1999, the fund lost about $25 \%$ of its assets through withdrawals. After mounting losses, Robertson announced the fund's liquidation in March 2000, just when prices of technology stocks started to tumble (Lewis (2001)). The fact that the manager positioned most strongly against the bubble ${ }^{10}$ had to liquidate just before the bubble peaked provides a vivid illustration of the liquidation risks that give rise to limits on arbitrage in Shleifer and Vishny (1997). The Quantum Fund suffered from outflows when technology stocks started to decline and it was still heavily invested in this segment. Overall, though, Soros fared better than Tiger. Unlike Tiger, the funds that chose to ride the bubble are still around.

\section{Did Hedge Funds Time Their Exposure in Individual Stocks?}

Having established that hedge funds were riding the bubble, we now turn to the important question of whether hedge funds did so deliberately-as predicted, for example, by the AB (2003) model—or whether they simply failed to understand that a bubble had developed. The fact that hedge funds did not exit the technology stock segment very aggressively around the peak of the bubble implies that this is a plausible alternative hypothesis. Yet, looking at aggregate holdings perhaps obscures more successful timing at the individual stock level. After all, the fact that the Nasdaq high P/S segment peaked in March 2000 does not mean that all member stocks peaked in that quarter. This is underscored by Table III, which shows the number of stocks that peaked in each quarter from 1999 to 2000, based on quarterly returns. Many stocks peaked before or in quarters subsequent to March 2000. Hence, it is possible that hedge funds' holdings of technology stocks in early 2000 were well chosen, in the sense that they were concentrated in stocks that did not crash yet. We investigate this possibility in the remainder of the paper.

\footnotetext{
${ }^{10}$ In fact, if we run our factor model (see Table II) for Tiger's Jaguar fund, we find evidence that the fund held a short position in technology stocks (in comparison, Figure 4a only provides evidence of a lack of long positions). Over the period January 1999 to March 2000, we obtain a negative weight on technology stocks of $w_{T}=-0.12$ for Jaguar (with a standard error of 0.04).
} 
Table III

\section{Distribution of Price Peaks of Nasdaq Technology (High P/S) Stocks}

For each stock, we construct a quarterly total return index from 1998 to 2000, from which we determine each stock's price peak during this period. The table presents the number of stocks peaking per quarter during 1999-2000. It includes only stocks that belong to the Nasdaq high P/S segment at the time of their peak.

\begin{tabular}{ccc}
\hline Year & Quarter & Number of Peaks \\
\hline 1999 & 1 & 58 \\
& 2 & 86 \\
& 3 & 38 \\
4 & 207 \\
2000 & 1 & 285 \\
& 2 & 98 \\
& 3 & 198 \\
& 4 & 49 \\
\hline
\end{tabular}

\section{A. Hedge Fund Holdings around Stock Price Peaks}

As a first approach to this question, we look at hedge fund holdings around the price peaks of individual stocks. For each stock, we construct a quarterly total return index from 1998 to 2000 . We define the price peak as the quarter-end at which this index takes its maximum value. To ensure that we can observe holdings several quarters before the peak, we restrict attention to stocks peaking in 1999 or 2000 . For each stock, we also calculate the proportion of outstanding shares that is held by hedge funds. Using an event study framework, we align these quarterly series of hedge fund holdings in event time. Event-time quarter 0 is the quarter of the price peak. We then take a value-weighted average across stocks within three different samples: high P/S Nasdaq stocks, other Nasdaq stocks, and NYSE/AMEX stocks.

Figure 5 presents the result. The first point to note is that for high P/S Nasdaq stocks, hedge funds owned a greater proportion of outstanding equity before than after the (quarterly) price peak. They held the maximum share of $0.54 \%$ one quarter before the price peak. At the end of the peak-quarter, this is already reduced to $0.40 \%$. (Standard errors are close to $0.02 \%$ for NYSE/AMEX stocks, and they vary between $0.02 \%$ and $0.04 \%$ for Nasdaq stocks.) There is a further decline in the postpeak quarters in which average returns are negative. Interestingly, hedge funds seem to be much more successful in timing their investments within the high $\mathrm{P} / \mathrm{S}$ segment of the Nasdaq than within other market segments. While hedge fund holdings before price peaks in the technology segment are almost twice as high as for NYSE/AMEX stocks, there is not much difference several quarters after the peak.

Hence, more so than the aggregate holdings data in Figure 2, these stockby-stock results suggest that hedge funds had some success in exiting before prices collapsed. In prepeak quarters, hedge funds held about twice as many shares as in postpeak quarters. For technology stocks, the average returns in 


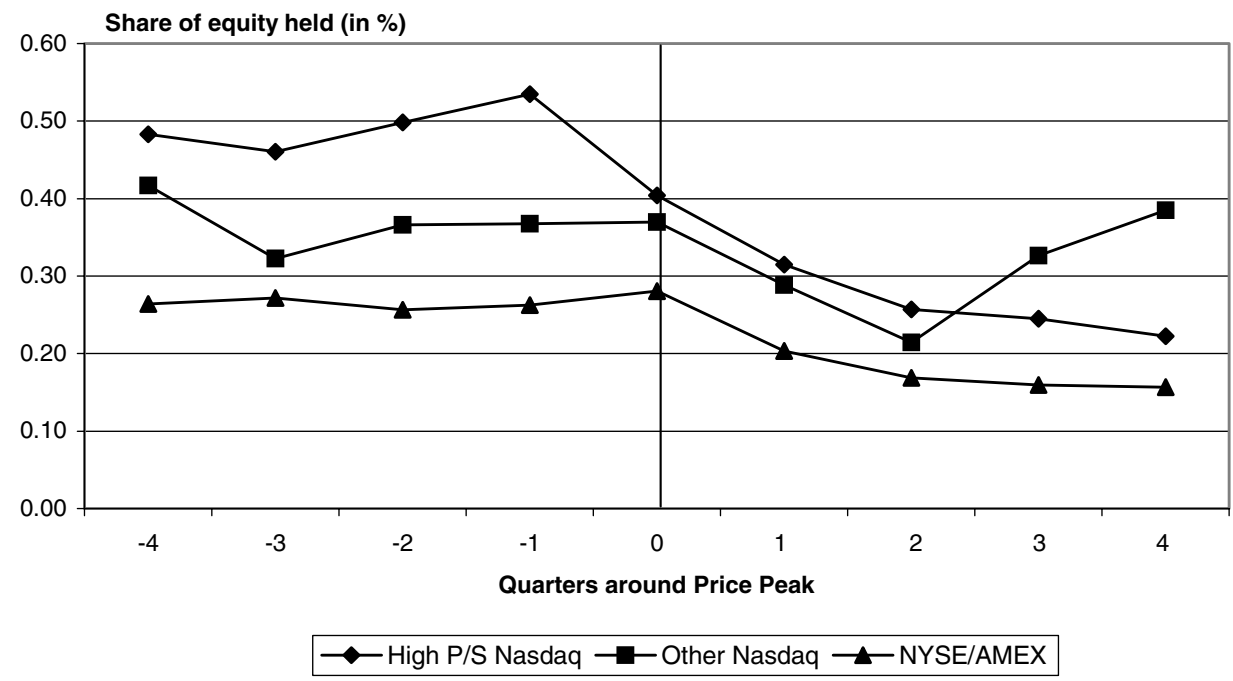

Figure 5. Average share of outstanding equity held by hedge funds around price peaks of individual stocks. For each stock, we construct a quarterly total return index from 1998 to 2000 , from which we determine each stock's price peak during this period. Each quarter, we also calculate the proportion of outstanding shares that is held by hedge funds. For stocks with peaks in 1999 or 2000, we align these time-series of holdings in event time (value-weighted), where the price peak is the event-time quarter 0 . We then average hedge fund holdings in event time across all stocks in the sample. The figure presents these event-time averages for three different samples of stocks: Stocks in the high P/S quintile of the Nasdaq, other Nasdaq stocks, and NYSE/AMEX stocks.

the postpeak quarters are in the range of $-20 \%$. Hedge funds managers let other investors bear a greater share of this price collapse than of the price run-up before the peak.

\section{B. Characteristics-Adjusted Performance}

If hedge fund managers indeed had skill in picking stocks and in timing the bubble on an individual stock level, this should also be detectable in a standard performance evaluation framework. In this subsection, we therefore look at portfolios that replicate the holdings of hedge fund managers-to the extent that they are visible in our quarterly data. We compare them to suitable benchmark portfolios to determine abnormal performance. Specifically, we form "copycat" funds that invest in aggregate hedge fund shareholdings at each quarter-end from March 1998 to December 2000. ${ }^{11}$ We form three of these copycat funds, one for the Nasdaq high P/S quintile, one for other Nasdaq stocks,

${ }^{11}$ Of course, $13 \mathrm{~F}$ filings are not public yet at the end of the quarter. Owing to the reporting deadline, it takes at least 45 more days for this information to become public. Hence, this copycat fund could not be implemented in this way in reality. 


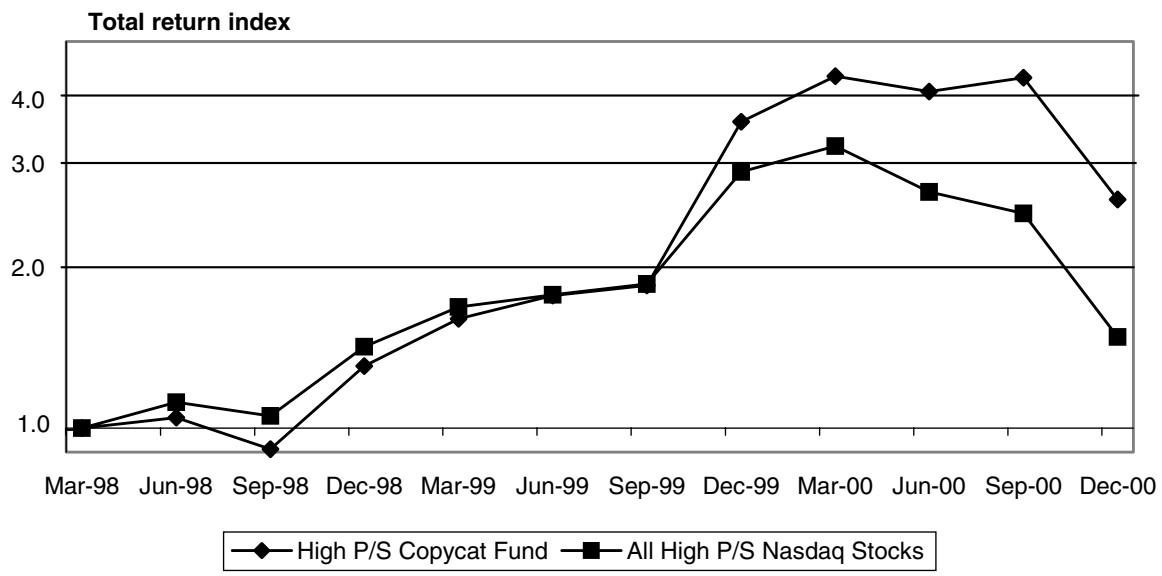

Figure 6. Performance of a copycat fund that replicates hedge fund holdings in the Nasdaq high P/S segment. At the end of each quarter, we form a portfolio that replicates aggregate hedge fund holdings in the Nasdaq high P/S segment as of that quarter-end. Stocks are held until the portfolio is rebalanced at the end of the next quarter. The figure shows the value-weighted buy-and-hold return on this portfolio and the portfolio of all high P/S Nasdaq stocks (log scale).

and one for NYSE/AMEX stocks. Within each copycat fund, we weight returns for each stock in proportion to the value of hedge fund holdings.

To get a first impression of hedge fund performance, Figure 6 plots the total return index of the Nasdaq high P/S copycat portfolio against the value-weighted return on the entire Nasdaq high P/S quintile. The results are intriguing. The figure shows that around the peak of the bubble-from September 1999 to September 2000 - technology stocks held by hedge funds performed much better than other technology stocks. This confirms what we conjectured earlier, namely that, in 2000, hedge funds holdings were concentrated in technology stocks that did not really crash yet.

Turning to a more formal evaluation of performance, we follow established methodology from the mutual fund literature (Daniel et al. (1997), Chen, Jegadeesh, and Wermers (2000)) and measure abnormal returns relative to characteristics-matched benchmark portfolios. To calculate benchmark returns, we sort all Nasdaq stocks into quintiles based on size, and we subsort within these groups, first into $\mathrm{P} / \mathrm{S}$ quintiles, and then into past 6-month return (momentum) quintiles. Returns are value-weighted. We repeat the same exercise for NYSE/AMEX stocks, which yields a second set of 125 benchmark portfolios. We calculate abnormal returns for each stock by subtracting the return of its matched benchmark portfolio.

Table IV presents the results. We compute performance measures separately for each of the four quarters following a $13 \mathrm{~F}$ report. For example, the copycat portfolio in the first row $(\mathrm{Qtr}+1)$ invests in stocks held by hedge funds at the end of March 1998, and it holds them until the end of June 1998, when the portfolio is rebalanced based on end-of-June 1998 filings, and so on. In the second 


\section{Table IV}

\section{Characteristics-Adjusted Performance of Hedge Fund Portfolio}

At the end of each quarter $t$, we form a portfolio that mimics aggregate hedge funds' holdings (Copycat), based on holdings reported in the end of quarter $t 13 \mathrm{~F}$ filings. We form three sets of copycat portfolios: One for the Nasdaq high P/S quintile, one for other Nasdaq stocks, and one for NYSE/AMEX stocks. We compute buy-and-hold returns for each quarter $t+1$ to $t+4$. Returns in the Copycat portfolio are weighted by the dollar-value of hedge funds' holdings (number of stocks times price). Portfolio returns are then averaged in event time. The first row reports the average return in quarter $t+1$, that is, in the first quarter following the $13 \mathrm{~F}$ report. The second row reports the return in quarter $t+2$, etc. The two left-hand sets of columns report the average number of stocks and market capitalization of the entire market segment (Total) and the Copycat portfolio. The first formation date is end of March 1998; the last one is end of December 2000. Abnormal returns are measured relative to size, $\mathrm{P} / \mathrm{S}$, and past 6-month returns characteristics-matched benchmark portfolios. Returns are given in percent per quarter.

\begin{tabular}{|c|c|c|c|c|c|c|c|}
\hline \multirow[b]{3}{*}{ Market Segment } & \multirow{3}{*}{$\begin{array}{l}\text { Qtrs. } \\
\text { after } 13 \mathrm{~F}\end{array}$} & \multirow{2}{*}{\multicolumn{2}{|c|}{ Number of Stocks }} & \multirow{2}{*}{\multicolumn{2}{|c|}{ Value in $\$ b n}}$. & \multirow{2}{*}{\multicolumn{2}{|c|}{$\begin{array}{c}\text { Qtrly. Abnormal } \\
\text { Returns }\end{array}$}} \\
\hline & & & & & & & \\
\hline & & Total & Copycat & Total & Copycat & Mean & $t$-Statistic \\
\hline \multirow{4}{*}{$\begin{array}{l}\text { High P/S Nasdaq stocks } \\
\text { (Technology Segment) }\end{array}$} & +1 & 720 & 320 & 2071 & 8.0 & 4.51 & $(1.87)$ \\
\hline & +2 & & & & & 2.71 & $(2.02)$ \\
\hline & +3 & & & & & 0.39 & $(0.22)$ \\
\hline & +4 & & & & & 1.01 & $(0.77)$ \\
\hline \multirow[t]{4}{*}{ Other Nasdaq stocks } & +1 & 3163 & 472 & 1236 & 4.1 & 0.55 & $(0.58)$ \\
\hline & +2 & & & & & 0.36 & $(0.30)$ \\
\hline & +3 & & & & & -1.64 & $(-1.12)$ \\
\hline & +4 & & & & & -0.89 & $(-0.55)$ \\
\hline \multirow[t]{4}{*}{ NYSE/AMEX stocks } & +1 & 2118 & 885 & 9891 & 25.0 & 0.24 & $(0.31)$ \\
\hline & +2 & & & & & 0.25 & $(0.31)$ \\
\hline & +3 & & & & & 0.32 & $(0.30)$ \\
\hline & +4 & & & & & -0.48 & $(-0.45)$ \\
\hline
\end{tabular}

row $(\mathrm{Qtr}+2)$, the June to September 1998 portfolios are built on March 1998 $13 \mathrm{~F}$ filings, the October to December 1998 portfolios are based on June 1998 filings, etc. The (arithmetic) mean abnormal returns in the technology segment are striking. The Qtr +1 copycat portfolio on average outperforms by $4.5 \%$ per quarter. The outperformance appears quite long-lived, as Qtr +2 adds some more abnormal returns, albeit at a lower magnitude. There is no reversal of this outperformance in $\mathrm{Qtr}+3$ and $\mathrm{Qtr}+4$. In economic terms, these magnitudes are large. Incorporating transaction costs would do little to change this. The quarterly turnover in the high $\mathrm{P} / \mathrm{S}$ copycat portfolio is about $25 \%$. A roundtrip trading cost of $1.5 \%$ - this is more toward the upper end of institutional trading costs (including price impact) for Nasdaq stocks ${ }^{12}$ —would then reduce

\footnotetext{
${ }^{12}$ Specifically, Keim and Madhavan (1997) report that total one-way trading costs for institutions, including price impact, are less than $0.7 \%$ for stocks in the top two Nasdaq size quintiles. Our portfolios are value-weighted and hence dominated by these large-cap stocks.
} 
the outperformance in $\mathrm{Qtr}+1$ to a still large 4.1\%. Of course, given our short sample period of 12 quarters, our statistical power to distinguish skill from luck is quite limited. It is rather surprising that the Qtr +1 and $Q \operatorname{tr}+2$ abnormal returns are statistically significant at the $10 \%$ and $5 \%$ levels, respectively, and it highlights the large magnitudes of abnormal returns.

We want to emphasize, though, that we do not aim to draw general conclusions about hedge fund manager stock-picking skills. What we can say based on Table IV and Figures 5 and 6 is that in this particular situation during the bubble period, hedge fund managers' technology stock picks performed much better than those of the average investor. The rather unusual nature of this outperformance is underscored by the fact that none of the abnormal returns for other Nasdaq stocks, or for NYSE/AMEX stocks, comes close to the outperformance figures we find in the technology segment. They are all much closer to zero and statistically insignificant.

Overall, these results support our earlier working assumption that hedge fund managers understood that technology stocks were overvalued and that prices would come down eventually. The evidence shows that they traded accordingly. The fact that their outperformance was concentrated in the technology segment is further consistent with the intuition expressed, for example, in $\mathrm{AB}$ (2003) and DSSW (1990b) that price bubbles present particularly good profit opportunities to rational speculators, if the sentiment of unsophisticated investors supporting the bubble is predictable to some extent. These potential gains are precisely the reason why riding a bubble can be a rational strategy in these models.

Of course, hedge fund trading strategies are likely to be more complicated than in these stylized models. So how did hedge funds achieve this outperformance? "Trend-following," which may involve rather complex technical trading rules, is a popular trading style among hedge funds (Fung and Hsieh (1997)). Some readers therefore wondered whether the outperformance we find could simply be the result of trading on a mechanical Jegadeesh and Titman (1993) type momentum rule. This is unlikely to be the case, however, because our performance benchmarks control for momentum. Yet, in its more complex sense, there could be some correspondence between trend-following and the behavior of rational speculators in bubble models. It may be that technical signals allow hedge funds (implicitly) to forecast the sentiment of less sophisticated investors, which is crucial in feedback-trader models of the DSSW (1990b) type, and the behavior of other speculators, which is emphasized in coordination-failure models such as AB (2003).

\section{Conclusions}

The efficient market hypothesis is based on the presumption that rational investors prevent price bubbles by trading against mispricing. In this paper, we study the behavior of some of the most sophisticated investors during a bubble period. Specifically, we analyze stock holdings of hedge funds during the technology bubble, 1998-2000. We establish two main facts. 
First, hedge funds were riding the technology bubble, not attacking it. On average, hedge fund stock portfolios were heavily tilted toward technology stocks. This suggests that short-sales constraints, emphasized in recent work on the technology bubble (Ofek and Richardson (2003), Cochrane (2002)), are not sufficient to explain the failure of rational speculative activity to contain the technology bubble. Short-sale constraints and arbitrage risks alone can rationalize reluctance to take short positions, but do not explain why sophisticated investors would buy into the overpriced technology sector.

Second, on a stock-by-stock basis, hedge funds reduced their holdings before prices collapsed. Within the technology segment-and only there-they outperformed standard characteristics-matched benchmarks. This suggests that hedge fund managers understood that prices of these stocks would eventually deflate. Our findings are consistent with the view that the investor sentiment driving the technology bubble was predictable to some extent, and that hedge funds were exploiting this opportunity. Under these conditions, riding a price bubble for a while can be the optimal strategy for rational investors, as, for example, in AB (2003).

\section{REFERENCES}

Abreu, Dilip, and Markus K. Brunnermeier, 2002, Synchronization risk and delayed arbitrage, Journal of Financial Economics 66, 341-360.

Abreu, Dilip, and Markus K. Brunnermeier, 2003, Bubbles and crashes, Econometrica 71, 173-204.

Ackermann, Carl, Richard McEnally, and David Ravenscraft, 1999, The performance of hedge funds: Risk, return, and incentives, Journal of Finance 54, 833-874.

Agarwal, Vikas, and Narayan Y. Naik, 2000, Multi-period performance persistence analysis of hedge funds, Journal of Financial and Quantitative Analysis 35, 327-342.

Agarwal, Vikas, Naveen D. Daniel, and Narayan Y. Naik, 2002, Determinants of money-flow and risk-taking behavior in the hedge fund industry, Working paper, London Business School.

Allen, Franklin, and Gary Gorton, 1993, Churning bubbles, Review of Economic Studies 60, 813836.

Baker, Malcolm, and Serkan Savasoglu, 2002, Limited arbitrage in mergers and acquisitions, Journal of Financial Economics 64, 91-116.

Bloomberg News, 1999, Hedge fund to curb investors' withdrawals, New York Times October 8, Section C, p. 22.

Brown, Steven J., and William N. Goetzmann, 2003, Hedge funds with style, Journal of Portfolio Management 29 (Winter), 101-112.

Brown, Steven J., William N. Goetzmann, and James Park, 2000, Hedge funds and the Asian currency crisis of 1997, Journal of Portfolio Management 26 (Summer), 95-101.

Brunnermeier, Markus K., 2001, Asset Pricing under Asymmetric Information: Bubbles, Crashes, Technical Analysis and Herding (Oxford University Press, Oxford).

Brunnermeier, Markus K., and Lasse H. Pedersen, 2002, Predatory trading, Working paper, Princeton University and NYU.

Campbell, John Y., Andrew W. Lo, and A. Craig MacKinlay, 1997, The Econometrics of Financial Markets (Princeton University Press, Princeton, NJ).

Chen, Hsiu-Lang, Narasimhan Jegadeesh, and Russ Wermers, 2000, The value of active mutual fund management: An examination of the stockholdings and trades of fund managers, Journal of Financial and Quantitative Analysis 35, 343-368.

Chevalier, Judith, and Glenn Ellison, 1997, Risk taking by mutual funds as a response to incentives, Journal of Political Economy 105, 1176-1200. 
Cochrane, John H., 2002, Stocks as money: Convenience yield and the tech-stock bubble, Working paper, NBER.

Cottier, Philipp, 1997, Hedge Funds and Managed Futures: Performance, Risks, Strategies, and Use in Investment Portfolios (Verlag Paul Haupt, Bern, Switzerland).

Daniel, Kent, Mark Grinblatt, Sheridan Titman, and Russ Wermers, 1997, Measuring mutual fund performance with characteristic-based benchmarks, Journal of Finance 52, 1035-1058.

DeLong, J. Bradford, Andrei Shleifer, Lawrence Summers, and Robert Waldmann, 1990a, Noise trader risk in financial markets, Journal of Political Economy 98, 703-738.

DeLong, J. Bradford, Andrei Shleifer, Lawrence Summers, and Robert Waldmann, 1990b, Positive feedback investment strategies and destabilizing rational speculation, Journal of Finance 45, $375-395$.

Dow, James, and Gary Gorton, 1994, Arbitrage chains, Journal of Finance 49, 819-849.

Fama, Eugene F., 1965, The behavior of stock-market prices, Journal of Business 38, 34-105.

Friedman, Milton, 1953, The case for flexible exchange rates, in Essays in Positive Economics (University of Chicago Press, Chicago).

Fung, William, and David A. Hsieh, 1997, Empirical characteristics of dynamic trading strategies, Review of Financial Studies 10, 275-302.

Fung, William, and David A. Hsieh, 2000, Measuring the market impact of hedge funds, Journal of Empirical Finance 7, 1-36.

Gompers, Paul A., and Andrew Metrick, 2001, Institutional investors and equity prices, Quarterly Journal of Economics 116, 229-260.

Griffin, John M., Jeffrey Harris, and Selim Topaloglu, 2002, Investor behavior over the rise and fall of Nasdaq, Working paper, Arizona State University.

Hamilton, James D., 1994, Time Series Analysis (Princeton University Press, Princeton, NJ).

Hart, Oliver D., and David M. Kreps, 1986, Price destablizing speculation, Journal of Political Economy 94, 927-952.

Jegadeesh, Narasimhan, and Sheridan Titman, 1993, Returns to buying winners and selling losers: Implications for stock market efficiency, Journal of Finance 48, 699-720.

Keim, Donald B., and Ananth Madhavan, 1997, Transaction costs and investment style: An interexchange analysis of institutional equity trades, Journal of Financial Economics 46, 265292.

Lamont, Owen, and Richard Thaler, 2003, Can the market add and subtract? Mispricing in tech stock carve-outs, Journal of Political Economy 111, 227-268.

Lewellen, Jonathan, 2003, Discussion of "The internet downturn: Finding valuation factors in spring 2000," Journal of Accounting and Economics 34, 237-247.

Lewis, William, 2001, Robertson hits out at 'irrational' markets, Financial Times (London Edition), March 31, p. 28.

Ljungqvist, Alexander P., and William J. Wilhelm, 2002, IPO allocations: Discriminatory or discretionary? Journal of Financial Economics 65, 167-201.

Mitchell, Mark, and Todd Pulvino, 2001, Characteristics of risk and return in risk arbitrage, Journal of Finance 56, 2135-2175.

Mitchell, Mark, Todd Pulvino, and Erik Stafford, 2002, Limited arbitrage in equity markets, Journal of Finance 57, 551-584.

Ofek, Eli, and Matthew Richardson, 2002, The valuation and market rationality of internet stock prices, Oxford Review of Economic Policy 18, 265-287.

Ofek, Eli, and Matthew Richardson, 2003, Dotcom mania: The rise and fall of internet stock prices, Journal of Finance 58, 1113-1137.

Pacelle, Mitchell, 1999, Soros to appoint a CEO after firm's chaotic year, Wall Street Journal, August 10, p. C1.

Pontiff, Jeffrey, 1996, Costly arbitrage: Evidence from closed-end funds, Quarterly Journal of Economics 111, 1135-1152.

Ritter, Jay R., and Ivo Welch, 2002, A Review of IPO activity, pricing, and allocations, Journal of Finance 57, 1795-1828.

Sharpe, William F., 1992, Asset allocation: Management style and performance measurement, Journal of Portfolio Management, Winter, 7-19. 
Shiller, Robert, 2000, Irrational Exuberance (Princeton University Press, Princeton, NJ).

Shleifer, Andrei, and Robert W. Vishny 1997, The limits of arbitrage, Journal of Finance 52, 35-55.

Wermers, Russ, 2000, Mutual fund performance: An empirical decomposition into stock-picking talent, style, transactions costs, and expenses, Journal of Finance 55, 1655-1695.

Wurgler, Jeffrey, and Ekaterina Zhuravskaya, 2002, Does arbitrage flatten demand curves for stocks? Journal of Business 75, 583-608. 